\title{
Metabolite Profiling of Ficus deltoidea's Most Active Fraction as Anti-Candida albicans Using UPLC-QToF-MS/MS
}

\author{
Nita Triadisti*, Sri Rahayu, Irfan Zamzani \\ Faculty of Pharmacy, Universitas Muhammadiyah Banjarmasin, Kalimantan Selatan, INDONESIA.
}

\begin{abstract}
Background: Ficus deltoidea is a medicinal plant known for treatment by ethnic Dayaks, Kalimantan and called Tabat Barito. Empirically, the majority of Tabat Barito leaves are used to treat candidiasis. Scientific data on F. deltoidea activity in its activity against candidiasis or candida are still minimal. Metabolite profiling from the most active fraction of $F$. deltoidea against Candida has not been reported. Objectives: This study aimed to explore the most active part of $F$. deltoidea leaves against $C$. albicans by obtaining the most active fraction and identification of compounds in the most active fraction through metabolite profiling using UPLC-QToF-MS/ MS. Methods: The leaves were macerated using solvents with an increase in polarity, fractionation was done by column chromatography, while antifungal activity assay was carried out by diffusion method. Metabolite profiling was done using LC-MS/MS. Results: Assay results of extracts from $F$. deltoidea leaves against $C$. albicans showed that the best activity was owned by ethyl acetate extracts, with an inhibition zone of more than $10 \mathrm{~mm}$. The strongest activity against $C$. albicans was shown by FrEA5 with an inhibition zone of $30.67 \pm 1.155 \mathrm{~mm}$, stronger than Voriconazole as a
\end{abstract}

positive control with inhibition zone: $19.75 \pm 0.5 \mathrm{~mm}$. The metabolites that can be identified in FrEA5 were Nigeglanine; 1,1,2,3,3-Pentamethylindane; and 1,1'-(1,1-Ethenediyl)bis(3-methylpiperazine). Conclusion: This research shows that FrEA5 is the most active fraction of $F$. deltoidea leaves against $C$. albicans and the compounds contained in FrEA5 include Nigeglanine; 1,1,2,3,3-Pentamethylindane; and 1,1'-(1,1-Ethenedyl)bis(3methylpiperazine).

Key words: C. albicans, Ficus deltoidea, FrEA5, Metabolite Profiling, UPLC-QTOF-MS/MS.

\section{Correspondence}

Nita Triadisti

Faculty of Pharmacy, Universitas Muhammadiyah Banjarmasin, Kalimantan Selatan-70114, INDONESIA.

Phone: +62-0511-3363002

Email: triadisti@umbjm.ac.id

DOI: 10.5530/jyp.2021.13.13

\section{INTRODUCTION}

Ficus deltoidea is a medicinal plant that is very well known for its use for treatment by ethnic Dayaks, Kalimantan. This plant in Kalimantan is called by the name Tabat Barito. Some parts of this plant have traditionally been used in medicine, such as the fruit to relieve headaches, roots and leaves to treat wounds. Simultaneously, the decoction of the leaves is very well known in treating female health problems such as menstruation problems and restoring the strength of the uterus after childbirth, especially to overcome candidiasis. ${ }^{1,2}$ Empirically, most Tabat Barito leaves are used to treat candidiasis, this has been done for generations without ever being proven scientifically.

Some of the activities of $F$. deltoidea that have been reported include: as an antinociceptive, ${ }^{2,3}$ antioxidant, ${ }^{4-6}$ anti-diabetic, ${ }^{4,7}$ antiangiogenic effect, ${ }^{8}$ antibacterial and anti-inflammatory. ${ }^{2}$ Scientific data on $F$. deltoidea in its activity against candidiasis or candida is still minimal, even though empirically, this plant has been widely used in the treatment of candidiasis. In the empiric treatment of candidiasis, the F. deltoidea part used is the leaves. The discovery of the most active parts of the leaves in the form of fractions and identifying compounds in the fractions will increase the benefits of this plant in the treatment of candidiasis.

This research was conducted to explore the most active part of $F$. deltoidea leaves against Candida albicans by obtaining the most active fraction and identification of compounds in the most active fraction through metabolite profiling using UPLC-QToF-MS/MS. Metabolite profiling from the most active fraction of $F$. deltoidea against $C$. albicans has not been reported.
Mass Spectrometry can analyze secondary metabolites with high selectivity, sensitivity and very potential in identifying metabolites. The existence of various atmospheric ionization methods, such as electrospray ionization (ESI), atmospheric pressure photoionization (APPI) and atmospheric pressure chemical ionization (APCI) enable the ionization of various classes of metabolites. ${ }^{9}$ Liquid Chromatography tandem Mass Spectrometry is an instrument with a hyphenated system that can analyze metabolite profiling with high validity and accuracy. ${ }^{10}$ This hyphenated method has been successfully used for profiling secondary metabolite in some natural product such as metabolite profiling compounds from Curcuma aeruginosa, ${ }^{11}$ metabolite profiling from ascidian Styela plicata,${ }^{12}$ secondary metabolite profiling from Peperomia pellucida, ${ }^{10}$ metabolite profiling from Lentinula edodes mycelium $^{13}$ and identification of metabolite from Annona crassiflora. ${ }^{14}$

Although several metabolite profiling analyzes have been carried out on several plants, metabolite profiling analysis of the active fraction of F. deltoidea on Candida has not been reported. Secondary metabolite compounds have been reported successfully isolated from F. deltoidea, among others: flavonoid compounds such as epigallocatechin, epicatechin, catechin, afzelechin, epiafzelechin, apigenin, luteolin, vitexin and isovitexin, ${ }^{15}$ epi-lupeol, moreteno $1{ }^{16}$ which of all the compounds that have been isolated have never been reported to have activity against Candida.

F. deltoidea scientific data about antifungal, especially against Candida albicans are still rarely found. Antifungal activity against C. albicans from methanol and chloroform extracts of Ficus deltoidea has been reported 
by Abdsamah et al (2012). ${ }^{17}$ Fractionation by column chromatography method to get the most active fraction of the F. deltoidea leaves so far has not been done. Therefore researchers feel the need to research to get a fraction of the $F$. deltoidea leaves, which has the best activity against $C$. albicans. The most active fraction obtained is expected to have better activity than the extract. Fractionation is also carried out to get an overview of compounds that have a role in their activity against $C$. albicans. Proving the efficacy of $F$. deltoidea is very important, so it can reveal the potential of native plants in Kalimantan as a provider of new therapeutic agents that can be developed to overcome candidiasis. This approach is applied to reveal secondary metabolites' content in the most active fraction of $F$. deltoidea leaves using LC-MS/MS. In this study, we used UPLC-QTOF-MS/MS for metabolite profiling of F. deltoidea leaves fractions.

\section{MATERIALS AND METHODS}

\section{Plant Material}

F. deltoidea leaves were obtained from Balangan, South Kalimantan, Indonesia. Fresh $F$. deltoidea leaves are washed under running water, dried at a temperature of $50-55^{\circ} \mathrm{C}$ in a drying oven and the dried leaves are crushed with a grinder. The leaves powder is then placed in a cold room until it is analyzed.

\section{Chemicals and Instrumentation}

Chemicals: acetone, ethyl acetate, chloroform, n-hexane and methanol (PT. Smart Lab Indonesia, Indonesia), Acetonitrile hyper grade for LC-MS/MS (Merck), ultrapure water, silica gel 70-230 mesh (Merck), TLC Plate - Silica gel $60 \mathrm{~F}_{254}$ (Merck), DMSO (Merck), formic acid (Merck), C. albicans ATCC 10231 (Thermo scientific), Potato Dextrose Agar (Merck), Voriconazole disc (Oxoid). Instrumentation: UV Lamp (Camag), Metabolite profiling was conducted using LC-MS/MS UPLC Xevo G2-XS QToF (Waters).

\section{Extraction Process}

The leaves powder was macerated using solvents with an increase in polarity starting from n-hexane, followed by ethyl acetate and methanol. Maceration was done until the filtrate looks almost colorless, then the filtrate obtained was collected and evaporated. The extract obtained was then weighed. Maceration was continued with ethyl acetate and methanol solvent. With the same procedure and treatment, ethyl acetate and methanol extracts will be obtained.

\section{Fractionation of Ficus deltoidea Leaves Extract}

Fractionation was done by gravity column chromatography using a gradient system, using the method adopted with slight modifications. ${ }^{18}$ A total of $20 \mathrm{~g}$ of the extract with the best activity was fractionated by column chromatography using silica gel (70-230 mesh) as a stationary phase. The mobile phase used was a mixture of solvents with a specific ratio so that a gradient elution system with different polarity was obtained, starting from a combination of solvents with low to high polarity. The extract was eluted, starting from the eluent $n$-hexane and ethyl acetate in a ratio of 10:0, 9:1, 8:2, 7:3 and so on until 0:10, followed by ethyl acetate and methanol in a ratio of 9: 1, 8:2, 7:3 and so on until $0: 10$. The result of elution was the storage of each $100 \mathrm{ml}$ volume. The reservoir was then evaporated and tested by thin-layer chromatography (TLC) to determine the chromatogram pattern. The beds with the same/ similar chromatogram pattern were then combined into one and then tested for antifungal activity against C. albicans.

\section{Anti-Candida albicans activity assay}

Anti-Candida albicans activity assay, using inhibitory zone tests performed on the various extracts of $F$. deltoidea and fractions resulting from fractionation of the most active extracts. The Anti-Candida albicans activity test was carried out by inhibition zone assay using a procedure adapted with slight modifications. ${ }^{19}$ The inhibition zone assay was carried out using the diffusion method. In this study, the species of fungus used was C. albicans. Anti-Candida albicans activity was evaluated by measuring the diameter of the inhibitory zone around the disk. Voriconazole was used as a positive control for C. albicans.

\section{Metabolite Profiling by UPLC-QTOF-MS/MS}

Metabolite profiling was performed using Ultra High Performance Liquid Chromatography-Quadrupole-Time of Flight-MS/MS (UPLC-QTof-MS/MS) System according to the literature ${ }^{10}$ with slight modification adjusting to the instrument condition. Liquid chromatographic separation was performed using UPLC Xevo G2$\mathrm{XS}$ with $\mathrm{BEH} \mathrm{C}_{18} 1.7 \mu \mathrm{m}$ column with eluent consisting of water with $0.1 \%$ formic acid (A) and acetonitrile with $0.1 \%$ formic acid (B). The system used a flow rate of $0.3 \mathrm{ml} /$ minute. The elution gradient can be seen in Table 1. ESI Ionization source and QToF mass analyzer were used for Mass Spectrometry analysis. Data acquisition was processed with Unifi software. The UPLC output system was connected to the mass spectrometer via the ESI interface and was operated in the positive ion detection mode. Condition in MS measurement was as follows: positive ion detection mode; the cone gas was set at $30 \mathrm{~V}$, capillary $0.8 \mathrm{Kv}$, cone gas flow $50 \mathrm{~L} / \mathrm{h}$, source temperature $120^{\circ} \mathrm{C}$ and desolvation temperature $500^{\circ} \mathrm{C}$.

\section{RESULTS}

Assay of n-hexane, ethyl acetate and methanol extract from $F$. deltoidea leaves against $C$. albicans showed that the best activity was owned by ethyl acetate extracts from $F$. deltoidea leaves, with an inhibition zone of $14.33 \pm 0.577 \mathrm{~mm}$. Thus fractionation was only carried out on ethyl extract acetate extract from $F$. deltoidea leaves. The assay result of each F. deltoidea leaves extract against C. albicans was shown in Table 2. Fractionation by column chromatography from the ethyl acetate extract of $F$. deltoidea leaves produced 11 fractions. Assay results on C. albicans from the fractions of $F$. deltoidea were shown in Table 3. FrEA5 was the most active fraction in inhibiting $C$. albicans with inhibition zones of $30.67 \pm 1.155 \mathrm{~mm}$. FrEA5 has better activity than Voriconazole (inhibition zone: $19.75 \pm 0.5 \mathrm{~mm}$ ), which was used as a standard in this assay.

Identifying the phytochemical composition in FrEA5 as the most active fraction was carried out using UPLC-QToF-MS / MS. The Unifi software

Table 1: The elution gradient system for metabolite profiling using
UPLC-QToF-MS/MS.
\begin{tabular}{|cccc}
\hline Time (min) & $\begin{array}{c}\text { Flow Rate (mL/ } \\
\text { min) }\end{array}$ & Composition A (\%) & $\begin{array}{c}\text { Composition B } \\
(\%)^{2}\end{array}$ \\
\hline 0.00 & 0.300 & 95.0 & 5.0 \\
1.00 & 0.300 & 95.0 & 5.0 \\
8.00 & 0.300 & 60.0 & 40.0 \\
11.00 & 0.300 & 0.0 & 100.0 \\
13.00 & 0.300 & 0.0 & 100.0 \\
16.00 & 0.300 & 95.0 & 5.0 \\
\hline
\end{tabular}

${ }^{1}$ Water with $0.1 \%$ formic acid

${ }^{2}$ Acetonitrile with $0.1 \%$ formic acid 
Table 2: Activity of $100 \%$ F. deltoidea leaves extracts against $C$. albicans.

\begin{tabular}{ccc} 
No. & Extract & $\begin{array}{c}\text { Diameter of Inhibition zones } \\
\text { (The mean } \pm \text { SD in } \mathrm{mm} \text { ) }\end{array}$ \\
\hline 1. & n-Hexane & 0 \\
2. & Ethyl acetate & $14.33 \pm 0.577$ \\
3. & Methanol & $7.33 \pm 0.577$ \\
\hline
\end{tabular}

${ }^{1}$ Data are mean \pm SD for triplicate measurements.

Table 3: Weight, eluent of column and activity of the F. deltoidea fractions against C. albicans (100\%).

\begin{tabular}{|c|c|c|c|}
\hline Fraction ${ }^{1}$ & $\begin{array}{l}\text { Weight } \\
\text { (g) }\end{array}$ & Eluent of column ${ }^{2}$ & $\begin{array}{l}\text { Diameter of Inhibition } \\
\text { zones }^{3} \text { (The mean } \pm \text { SD } \\
\text { in } \mathrm{mm} \text { ) }\end{array}$ \\
\hline FrEA1 & 0.242 & $H / E=10: 0-9: 1$ & $7.67 \pm 0.577$ \\
\hline FrEA2 & 0.322 & $H / E=9: 1$ & $14.67 \pm 1.155$ \\
\hline FrEA3 & 0.431 & $H / E=9: 1-8: 2$ & $0 \pm 0$ \\
\hline FrEA4 & 0.302 & $H / E=8: 2$ & $0 \pm 0$ \\
\hline FrEA5 & 2.048 & $H / E=8: 2-7: 3$ & $30.67 \pm 1.155$ \\
\hline FrEA6 & 0.822 & $H / E=8: 2-7: 3$ & $14.00 \pm 1.000$ \\
\hline FrEA7 & 1.867 & $H / E=6: 4-5: 5$ & $11.67 \pm 0.577$ \\
\hline FrEA8 & 1.924 & $H / E=5: 5$ & $15.67 \pm 0.577$ \\
\hline FrEA9 & 1.564 & $H / E=5: 5-4: 6$ & $15.67 \pm 1.155$ \\
\hline FrEA10 & 2.422 & $H / E=4: 6-3: 7$ & $28.33 \pm 1.528$ \\
\hline FrEA11 & 4.112 & $\begin{aligned} H / E & =2: 8-\mathrm{E} / \mathrm{M} \\
& =0: 10\end{aligned}$ & $25.67 \pm 1.155$ \\
\hline
\end{tabular}

${ }^{1}$ FrEA1-11 $=$ fractions from ethyl acetate extract

${ }^{2} \mathrm{H}=\mathrm{n}$-Hexane, $\mathrm{E}=$ ethyl acetate, $\mathrm{M}:$ methanol.

${ }^{3}$ Data are mean \pm SD for triplicate measurements.

processed the data obtained, so an overview of compounds contained in FrEA 5 was obtained. The secondary metabolites that can be identified in FrEA5 can be seen in Table 4. The chromatogram and product ion mass of each compound from FrEA5 using UPLC-QToF-MS / MS can be seen in Figures 1,2 and 3.

\section{DISCUSSION}

F. deltoidea (Tabat Barito) is a medicinal plant that is well known by the Dayak ethnic of Kalimantan in treating candidiasis, but scientific data related to this matter is still rare. The compounds in Tabat Barito, which have the potential for candidiasis have never been revealed. This study was conducted to obtain the most active fraction of $C$. albicans and reveal the most active fraction compounds using UPLC-QToF-MS / MS.

The results of the activity assay of $F$. deltoidea leaves extract against $C$. albicans showed that $\mathrm{n}$-hexane extract did not have inhibitory activity against $C$. albicans. In contrast, methanol extract had weak inhibitory activity against $C$. albicans. The best activity was shown ethyl acetate extract from $F$. deltoidea leaves, with inhibition zones $14.33 \pm 0.577 \mathrm{~mm}$, so that fractionation was only carried out on ethyl acetate extracts from F. deltoidea leaves.

Fractionation of ethyl acetate extract from $F$. deltoidea leaves was carried out by column chromatography method. This fractionation was done to aim so that the active fractions can be separated from the less/inactive fractions. The fractionation of ethyl acetate extract from $F$. deltoidea leaves resulted in 11 fractions (Table 2) and after the activity assay of
Table 4: Determination of metabolite in FrEA5 using UPLC-QToF-MS/ MS in positive ion detection mode.

\begin{tabular}{cccc}
\hline $\begin{array}{c}\text { Observed RT } \\
(\min )\end{array}$ & Formula & $\begin{array}{c}\text { MS-MS } \\
(\mathrm{m} / \mathrm{z})\end{array}$ & Compound \\
\hline 9.22 & $\mathrm{C}_{14} \mathrm{H}_{20}$ & 211.1458 & $1,1,2,3,3$-Pentamethylindane \\
9.01 & $\mathrm{C}_{12} \mathrm{H}_{24} \mathrm{~N}_{4}$ & 225.2087 & $\begin{array}{c}1,1^{\prime} \text {-(1,1-Ethenediyl)bis(3- } \\
\text { methylpiperazine) }\end{array}$ \\
& $\mathrm{C}_{12} \mathrm{H}_{14} \mathrm{~N}_{2} \mathrm{O}$ & 203.1171 & Nigeglanine \\
\hline
\end{tabular}
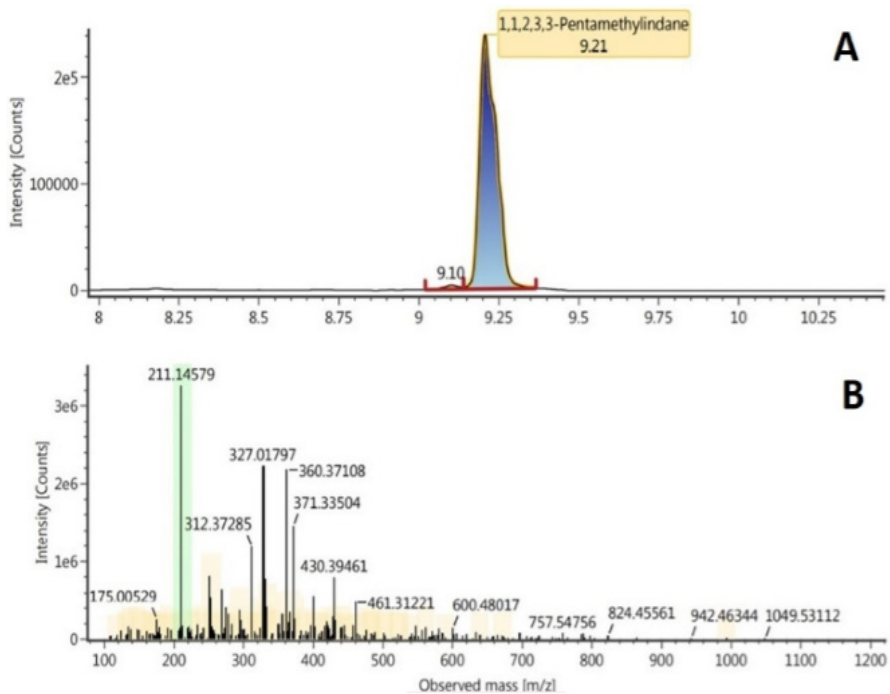

Figure 1: Chromatogram (A) and product ion mass spectra (B) of 1,1,2,3,3-Pentamethylindane.
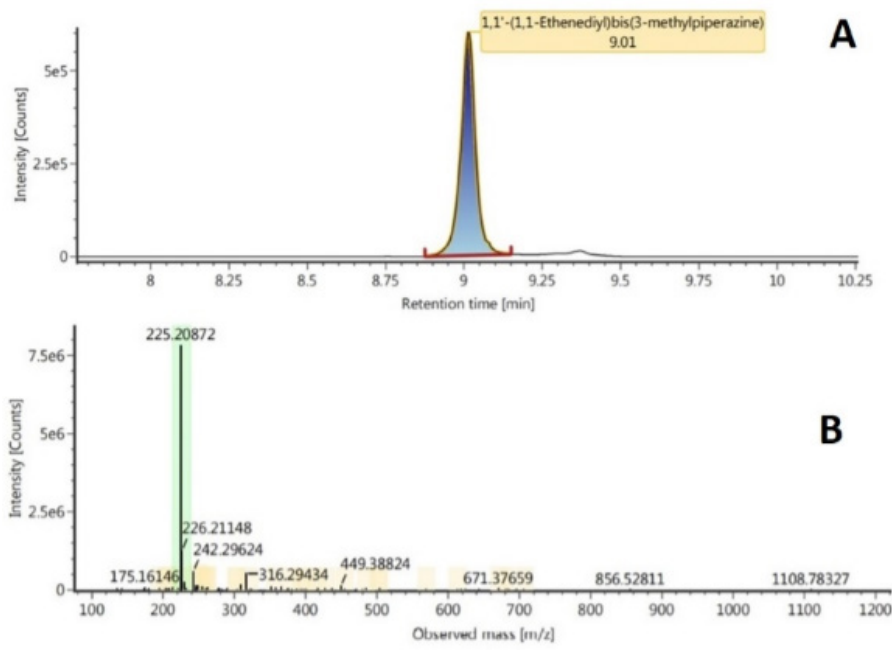

Figure 2: Chromatogram (A) and product ion mass spectra (B) of 1,1'-(1,1-Ethenediyl)bis(3-methylpiperazine).

11 fractions, there were differences in activity between the fractions. Some fractions had weaker activity than extracts and some fractions had stronger activities than extracts (Table 2). The fractionation result shows that there has been a separation of active fractions from less/inactive fractions. Fractions 5, 10 and 11 of the ethyl acetate extract of $F$. deltoidea leaves (FrEA5, FrEA10 and FrEA11) showed the potential to inhibit the growth of $C$. albicans, which was more potent than the other fractions with inhibition zones: $30.67 \pm 1.155 \mathrm{~mm} ; 28.33 \pm 1.528 \mathrm{~mm}$ and 25.67 

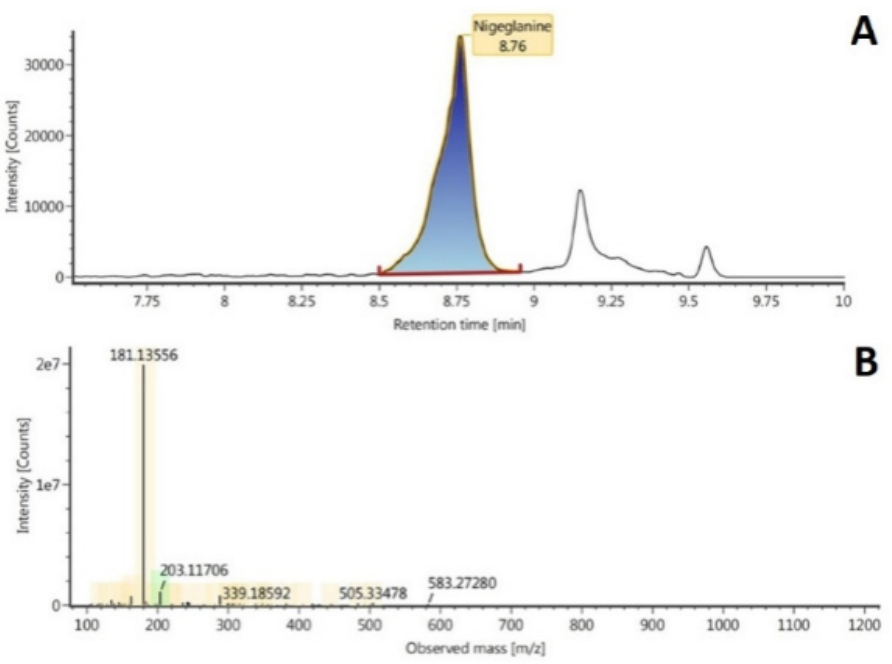

Figure 3: Chromatogram (A) and product ion mass spectra (B) of Nigeglanine.$$
\text { A }
$$

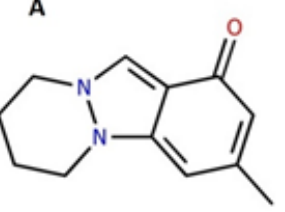

Nigeglanine
B

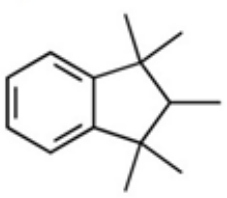

1,1,2,3,-Pentamehthlindane 1,1 -(1,1-Ethenediy Dbis(3-methylpipenzine)
C

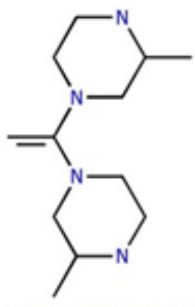

Figure 4: Chemical structure of (A) Nigeglanine, (B) 1,1,2,3,3-Pentamethylindane, (C) 1,1'-(1,1-Ethenediyl)bis(3-methylpiperazine).

$\pm 1.155 \mathrm{~mm}$, respectively. FrEA5 showed the strongest activity against C. albicans with an inhibition zone of $30.67 \pm 1.155 \mathrm{~mm}$. Inhibition of C. albicans growth from FrEA5, FrEA10 and FrEA11 was more potent than Voriconazole as a positive control with inhibition zone: $19.75 \pm 0.5$ mm. Result assay shows that FrEA5, FrEA10 and FrEA11 have excellent potential to be developed in candidiasis and FrEA5 shows as the most active fraction.

Activity assay against C. albicans showed that the fraction obtained from column chromatography has a stronger activity than the extract's origin. This can occur because an increase in activity after fractionation results from the separation of active phytoconstituents from inactive phytoconstituents. Previous studies, especially on F. deltoidea leaves, showed that $F$. deltoidea leaves contained alkaloids, flavonoids and terpenoids. ${ }^{16,20}$

FrEA5 as the fraction that has the best activity then identified the compounds contained therein using UPLC-QToF-MS/MS. The strategy of identifying metabolite using UPLC-QToF-MS/MS is based on peak analysis at a specific retention time and then compared to the database. ${ }^{21}$ Determining the concentration can make better separation with a shorter analysis time. ${ }^{22}$ In various metabolite profile analyzes using UPLCQTOF-MS / MS, it has been reported that this method is more selective and sensitive in metabolite profiling compared to other chromatographic techniques. ${ }^{23} \mathrm{MS}$ analysis with Quadrupole and Time of Flight (QToF) as a mass analyzer can detect various compounds. Besides QToF MS can provide mass information with high accuracy and precision, so that the structure's identification becomes more accurate. ${ }^{24}$

FrEA5 profiling using UPLC-QToF-MS / MS has succeeded in uncovering the compounds contained in FrEA5. These compounds include
Nigeglanine; 1,1,2,3,3-Pentamethylindane; and 1,1'-(1,1-Ethenediyl) bis(3-methylpiperazine). The chemical structure of these compounds can be seen in Figure 4.

Nigeglanine and 1,1'-(1,1-Ethenediyl)bis(3-methylpiperazine) are alkaloid compounds, while 1,1,2,3,3-Pentamethylindane is a terpenoid compound. Several journals have reported the activity of terpenoids and alkaloids as antimicrobials, including against Candida albicans. Some of the alkaloids that have been reported to have activity in inhibiting candida growth were the alkaloid berberine and alkaloids from Myristica fragrans where their mechanism of action against candida has been reported to cause mitochondrial dysfunction..$^{25}$ Terpenoids reported having activity against candida include farnesol, menthol, nerol, linalool, isopulegol and carvone. ${ }^{26}$ The mechanism of terpenoids as antifungal, among others, is by inhibiting the formation of cell walls, destroying fungal mitochondria by inhibiting the action of mitochondrial dehydrogenases and killing cells by interfering efflux pumps. ${ }^{27}$ The compounds detected from F. deltoidea using UPLC-QToF-LC/MS-MS (Nigeglanine; 1,1,2,3,3-Pentamethylindane; and 1,1'-(1,1-Ethenediyl) bis(3-methylpiperazine)) has never been reported for its activity against C. albicans.

\section{CONCLUSION}

Based on the above assay results, it can be reported that Ficus deltoidea leaves have activity as anti-Candida albicans, especially FrEA5, as the most active fraction against $C$. albicans, which was successfully separated by column chromatography. Metabolite profiling has successfully revealed the compounds in FrEA5 as the most active fraction of $F$. deltoidea leaves include Nigeglanine; 1,1,2,3,3-Pentamethylindane; and 1,1'-(1,1-Ethenediyl)bis(3-methylpiperazine).

\section{ACKNOWLEDGEMENT}

Authors thank PDP Grant 2019 from the Ministry of Research, Technology and Higher Education of the Republic of Indonesia for providing research opportunities.

\section{CONFLICT OF INTEREST}

The authors have no conflict of interest to declare.

\section{ABBREVIATIONS}

UPLC : Ultra High Performance Liquid Chromatography; QToF: Quadrupole Time of Fligh; MS: Mass Spectrometry; ESI: Electrospray Ionization; APPI: Atmospheric Pressure Photoionization; APCI: Atmospheric Pressure Chemical Ionization.

\section{REFERENCES}

1. Suryati S, Nurdin H, Dachriyanus D, Hj LMN. Structure Elucidation Of Antibacterial Compound From Ficus deltoidea Jack Leaves. Indones J Chem. 2011;11(1):67-70. doi:10.22146/ijc.21422

2. Bunawan H, Amin NM, Bunawan SN, Baharum SN, Mohd NN. Ficus deltoidea jack: A review on its phytochemical and pharmacological importance. Evidence-based Complement Altern Med. 2014;2014(902734):1-9. doi:10.1155/2014/902734

3. Sulaiman MR, Hussain MK, Zakaria ZA, et al. Evaluation of the antinociceptive activity of Ficus deltoidea aqueous extract. Fitoterapia. 2008;79(7-8):557-61. doi:10.1016/j.fitote.2008.06.005

4. Hakiman M, Maziah M. Non enzymatic and enzymatic antioxidant activities in aqueous extract of different Ficus deltoidea accessions. J Med Plants Res. 2009;3(3):120-31.

5. Omar MH, Mullen W, Crozier A. Identification of proanthocyanidin dimers and trimers, flavone C-glycosides and antioxidants in Ficus deltoidea, a malaysian herbal tea. J Agric Food Chem. 2011;59(4):1363-9. doi:10.1021/jf1032729

6. Sirisha N, Sreenivasulu M, Sangeeta K, Madhusudhana CC. Antioxidant properties of Ficus Species: A review. Int J PharmTech Res. 2010;2(4):2174-82.

7. Rosnah J, Khandaker MM, Boyce AN. Ficus deltoidea: Review on background 
and recent pharmacological potential. J Agron. 2015;14(4):310-8. doi:10.3923/ ja.2015.310.318

8. Shafaei A, Syima MN, Nassar ZD, Aisha AFA, Abdul MAMS, Ismail Z Antiangiogenic effect of Ficus deltoidea jack standardised leaf extracts. Trop $J$ Pharm Res. 2014;13(5):761-8. doi:10.4314/tjpr.v13i5.16

9. Xiao JF, Zhou B, Ressom HW. Metabolite identification and quantitation in LC MS/MS-based metabolomics. Trends Anal Chem. 2012;32:1-14. doi:10.1016/j. trac.2011.08.009

10. Ahmad I, Mulia K, Yanuar A, Mun'im A. Metabolite profiling analysis of conventional and non-conventional extraction methods on secondary metabolite from Peperomia pellucida (L.) Kunth using UPLC-QToF-MS/MS System. J Young Pharm. 2018;10(2):s40-4. doi:10.5530/jyp.2018.2s.8

11. Septaningsih DA, Darusman LK, Afendi FM, Heryanto R. Liquid chromatography mass spectrometry (LC-MS) fingerprint combined with chemometrics for identification of metabolites content and biological activities of Curcuma aeruginosa. Indones J Chem. 2018;18(1):43-52. doi:10.22146/ijc.25456

12. Palanisamy SK, Trisciuoglio D, Zwergel C, DelBufalo D, Mai A. Metabolite profiling of ascidian Styela plicata using LC-MS with multivariate statistical analysis and their antitumor activity. J Enzyme Inhib Med Chem. 2017;32(1):61423. doi:10.1080/14756366.2016.1266344

13. Tang L, Shang J, Song $C$, et al. Untargeted Metabolite Profiling of Antimicrobial Compounds in the Brown Film of Lentinula edodes Mycelium via LC-MS/MS Analysis. ACS Omega. 2020;5(13):7567-75. doi:10.1021/acsomega.0c00398

14. Demarque DP, Dusi RG, DeSousa FDM, et al. Mass spectrometry-based metabolomics approach in the isolation of bioactive natural products. Sci Rep. 2020;10(1):1-9. doi:10.1038/s41598-020-58046-y

15. Nurmaida DLK, Rafi M, Heryanto R. Metabolite Profiling of Tabat Barito (Ficus deltoidea) Using UPLC-QTOF-MS/MS. J Pure Appl Chem Res. 2018;7(2):100-8. doi:10.21776/ub.jpacr.2018.007.02.374

16. Murni A, Hanif N, Kita M, Darusman LK. Methyl 10-Epi-Pheophorbide a From Mcf-7 Cells Active Layer of the Indonesian Ficus deltoidea Jack Leaves. Int J Pharm Pharm Sci. 2017;9(8):183. doi:10.22159/ijpps.2017v9i8.18750

17. Abdsamah O, Zaidi NTA, Sule AB. Antimicrobial activity of Ficus deltoidea Jack
(Mas Cotek). Pak J Pharm Sci. 2012;25(3):675-8. http://www.ncbi.nlm.nih.gov/ pubmed/22713960

18. Triadisti N, Sauriasari R, Elya B. Fractionation and $\alpha$-glucosidase inhibitory activity of fractions from Garcinia hombroniana pierre leaves extracts. Pharmacogn J. 2017;9(4):488-92. doi:10.5530/pj.2017.4.79

19. Silfi ANS, Ahmad I, Elya B, Malik A, Hanafi M. Pharmacognostic and antimicrobial studies of Garcinia latissima miq. Leaves (Clusiaceae). Pharmacogn J. 2017;9(4):493-8. doi:10.5530/pj.2017.4.80

20. Bunawan H, Amin NM, Bunawan SN, Baharum SN, Mohd NN. Ficus deltoidea jack: A review on its phytochemical and pharmacological importance. Evidencebased Complement Altern Med. 2014;2014:1-8. doi:10.1155/2014/902734

21. Wolfender JL, Marti G, Thomas A, Bertrand S. Current approaches and challenges for the metabolite profiling of complex natural extracts. J Chromatogr A. 2015;1382:136-64. doi:10.1016/j.chroma.2014.10.091

22. Cechinel-Filho V. Plant Bioactives and Drug Discovery: Principles, Practice and Perspectives. New Jersey: John Wiley and Sons, Inc. 2012 doi:10.1002/9781118260005

23. Grata E, Guillarme D, Glauser G, et al. Metabolite profiling of plant extracts by ultra-high-pressure liquid chromatography at elevated temperature coupled to time-of-flight mass spectrometry. J Chromatogr A. 2009;1216(30):5660-8. doi:10.1016/j.chroma.2009.05.069

24. Li SL, Song JZ, Choi FFK, et al. Chemical profiling of Radix Paeoniae evaluated by ultra-performance liquid chromatography/photo-diode-array/quadrupole time-of-flight mass spectrometry. J Pharm Biomed Anal. 2009:49(2):253-66. doi:10.1016/j.jpba.2008.11.007

25. Dhamgaye S, Devaux F, Vandeputte $P$, et al. Molecular mechanisms of action of herbal antifungal alkaloid berberine, in Candida albicans. PLoS One. 2014;9(8):1 9. doi:10.1371/journal.pone.0104554

26. Raut JS, Shinde RB, Chauhan NM, Mohan KS. Terpenoids of plant origin inhibit morphogenesis, adhesion and biofilm formation by Candida albicans. Biofouling. 2013;29(1):87-96. doi:10.1080/08927014.2012.749398

27. Nazzaro F, Fratianni F, Coppola R, DeFeo V. Essential oils and antifungal activity. Pharmaceuticals. 2017;10(4):1-20. doi:10.3390/ph10040086

Article History: Submission Date : 31-08-2020; Revised Date : 02-11-2020; Acceptance Date : 06-12-2020

Cite this article: Triadisti N, Rahayu S, Zamzani I. Metabolite Profiling of Ficus deltoidea's Most Active Fraction as Anti-Candida albicans Using UPLC-QToF-MS/ MS. J Young Pharm. 2021;13(1):58-62. 